\title{
Accelerometer as Land Movement Early Detection with Internet of Thing (IoT) Concept
}

\author{
Firmansyah M S Nursuwars ${ }^{1,3}$, Neng I Kurniati ${ }^{2,3}$ \\ \{firmansyah@unsil.ac.id ${ }^{1}$, Neng Ika Kurniati ${ }^{2}$ \} \\ Jurusan Informatika, Fakultas Teknik, Universitas Siliwangi, \\ Tasikmalaya, Jawabarat ${ }^{3}$
}

\begin{abstract}
Tasikmalaya Regency which is geographically mountainous and has slopes makes the land unstable. According to data from the National Disaster Management Agency (BNPB) in 2017, Tasikmalaya Regency is the third largest district / city in West Java that has landslide prone locations. The landslide disaster caused direct damage such as damage to public facilities, agricultural land, or community activities which were hampered. The magnitude of losses caused by landslides due to loss of property and even lives, is due to the lack of even the absence of early detection of land movements that can be used to detect the initial occurrence of landslides. The main problem of the disaster detection system, aside from how to give a warning to citizens about the potential for disasters, is how the system provides a valid warning as a sign of natural disasters. The system is designed using an accelerometer sensor to detect Land movement, by comparing the XYZ axis values on the accelerometer sensor when it stops and when it moves. With the use of an accelerometer sensor the system can detect Land movements both sideways, forward and downward movements.
\end{abstract}

Keywords: Accelerometer, Disaster, Landslide, Land Movement.

\section{Introduction}

Landslides are a common occurrence on slopes, both natural slopes and man-made slopes [1]. It can be triggered by external mechanisms such as undercutting of a slope, or by gradual processes such as weathering [2]. Landslides often occur in Indonesia [1], one of which is in the Tasikmalaya Regency area. Geographically a mountainous area and has slopes - slopes make the land unstable. The landslide disaster caused direct damage such as damage to public facilities, agricultural land, or community activities which were hampered.

According to data from the National Disaster Management Agency (BNPB) in 2017, Tasikmalaya Regency is the third category with the largest regency / city in West Java that has landslide prone locations. Based on the recapitulation of data published by the Regional Disaster Management Agency (BPBD) of Tasikmalaya Regency in 2017 there were 104 incidents prone to landslides from 39 Sub-Districts of Tasikmalaya District which continued to increase from previous years [3].

Of the many landslides that have occurred, the process of monitoring Landslides is still very rare, even though the tool is very useful for detecting potential landslides, so that if a landslide actually occurs, then the evacuation process has been carried out before. Sustainability like this is able to reduce losses and loss of life. 
The use of GPS for detecting ground movements is considered to be ineffective, because GPS depends on the quality of the satellite signal obtained [4], the lack of satellite signals due to bad weather or objects that block the GPS can cause detection errors, because the GPS shows changes in the position of the device. The use of other sensors such as ultrasonic sensors that work to measure the distance of detection of certain objects will be problematic if there are objects that block the sensor with reference distance objects. the use of accelerometer sensors is expected to detect natural symptoms as a sign that landslides will occur accurately because it only measures the acceleration of gravity of the earth [5].

The use of the accelerometer sensor in a landslide detector by comparing the XYZ axis value of the sensor when it is not move with the $\mathrm{XYZ}$ axis value when the sensor moves sideways, front, back, up or down. The difference obtained from the sensor axis value can indicate the ground movement is taking place. Using an accelerometer sensor can create a ground motion detection system that is reliable and low cost. Utilization of the IoT system in a ground motion detection system can be an early detection tool in landslides.

\section{Related work}

The landslides detector has been made by [2][6][7][8][9][10][11][12][13]. Reference [2][6] is the result of the same developer, which was published in 2 different journals, this study uses strain gauge piezometer sensors, vibrating wire piezometer, dielectric moisture sensors, tiltmeter and geophone to detect landslides. Data from the acquisition of 5 sensors are stored in the DB Server contained in the Field Management Center using the Wirellesss Sensor Network (WSN) standard IEEE 802.11b with bandwidth of $11 \mathrm{Mbps}$ using TCP / UDP. Data from the Field Management Center will be sent to the Data Management Center using satellites. reference [7] is a journal that discusses in more detail about geophone sensors used in research [2][6].

References [8] builds a system that detects soil movements using 2 types of sensors namely physical sensors and social sensors, physical sensors consisting of earthquake sensors using seismometers and weather satellites for rainfall, social sensors are filters of social media content such as twitter and instagram published by social media users.

Reference [9][10][11][12] is a landslides detection system using image processing method by comparing images before and after landslides, the image used is an image taken from a satellite image or an image taken by the camera normal.

Refernsi [13] emphasizes how to provide resources to the system of detecting ground movements without questioning how the system detects the occurrence of landslides.

This study discusses the early detection system of cost-effective soil movement using an Accelerometer sensor with IoT facilities, research on the use of accelerometer sensors has been done in journals [14], research on networks has been done in journals [15][16] and research on IoT has been done in journals [17]. 


\section{Proposed Design}

\subsection{Blok Diagram of the System}

Figure. 1 shows a diagram block of an early detection system for landslides using the Accelerometer Sensor. The accelerometer sensor is installed on a NodeMCU V.3 called the client node. Each installed client node will be connected to a nearby wifi repeater. WiFi repeater is connected to a WiFi Access Point that is connected to a $\mathrm{PC}$ that functions as a server. A network topology of the landslides detection system can be seen in Figure. 2.

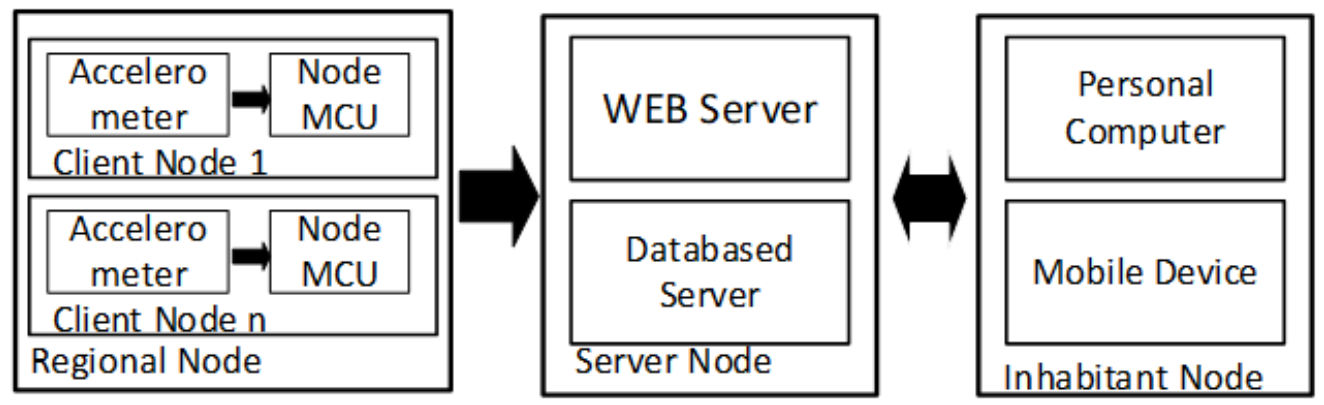

Figure. 1. System Block Diagram

The client node will send accelerometer sensor data to the database server every 5 minutes when there is no landslides, but if accelerometer sensor detects data changes the client node will immediately send data to the server. Client node that installed close together, functioning to validate each other for the process of detecting landslides. position change of the accelerometer on one client node does not necessarily provide a system notification to the inhabitant that there is landslides. The system will state that there is landslides if more than 1 client node that is close together (installed in one regional node) states that there is a change in the value on the accelerometer sensor.

The system will give a warning on the citizens' mobile devices in the form of notifications when the system states that there is landslides, landslides data can be seen in real time by inhabitant by accessing web-based applications and cellular applications 


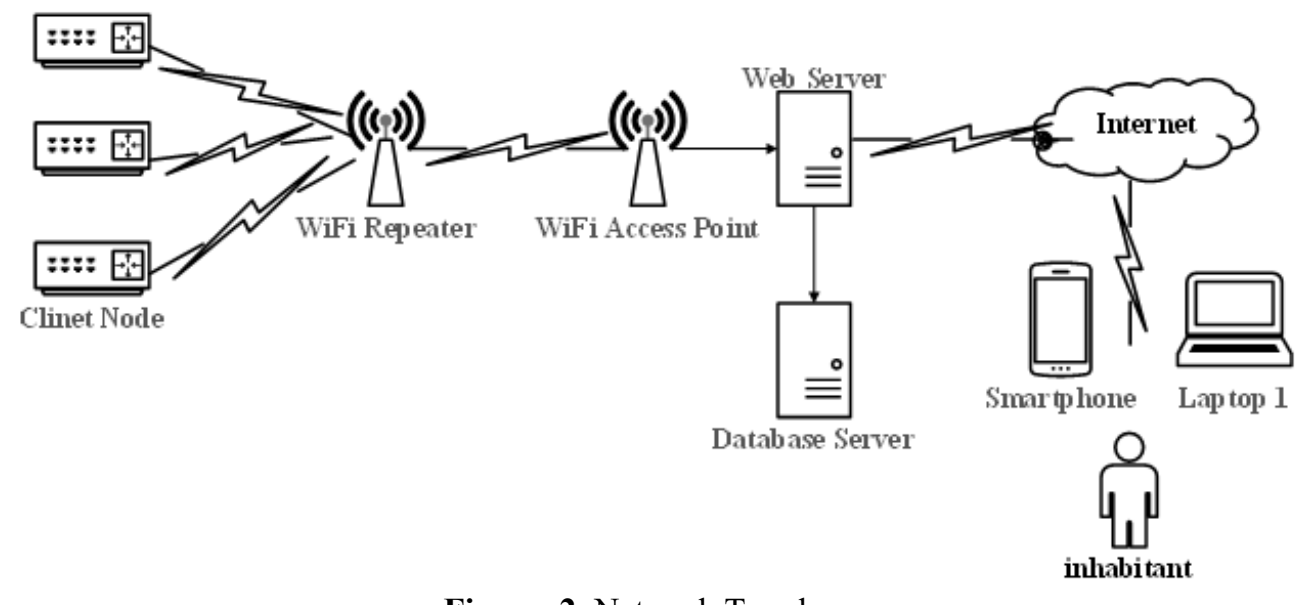

Figure. 2. Network Topology

\subsection{Flowchart of the System}

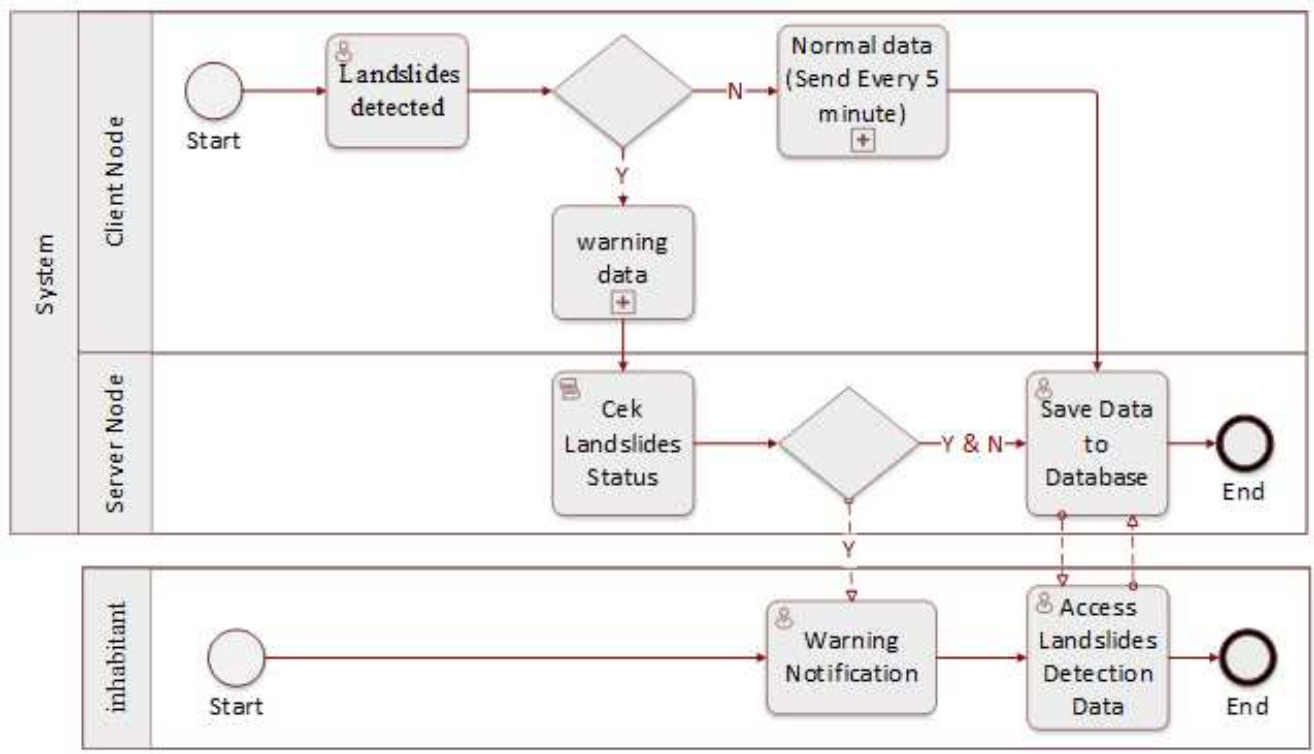

Figure. 3. Flowchart of the system

The system flow chart is taken using a BPMN diagram which can be seen in Figure. 3, the system starts from the accelerometer sensor initialization system whether there is or no change in the appropriate acceleration data, if no data changes occur, the client point will send data detection every 5 minutes. if there is a point detection the client will immediately send data to the server. Detection data will be analyzed by the server whether there is a landslide or not, if the server declares a landslide by comparing data from 1 client node with another client node, 
the server will send a warning notification to the mobile application. Data sent by client nodes and stored on node servers can be accessed by inhabitant in real time using web-based applications

\subsection{Circuit Analysis}

Figure. 4 shows the circuit diagram of client node, the client node consisting of nodemcu v.3 component as the heart of the system and MPU6050 series accelerometer sensor to measure proper acceleration, MPU6050 installed on D1 NodeMCU pin for SCL pin and SDA pin installed on D2 NodeMCU pin.

The red leds are installed on the D3 nodeMCU pin and the blue led are installed on the D4 nodeMCU pin. The blue LED will light up and the red led will turn off when the system is turned on, if there is a change in the proper acceleration value on the accelerometer sensor which indicates there is ground movement, then the red led is light up and the blue led is off. Once the system is idle again, the blue LED will light up and the red led will turn off.

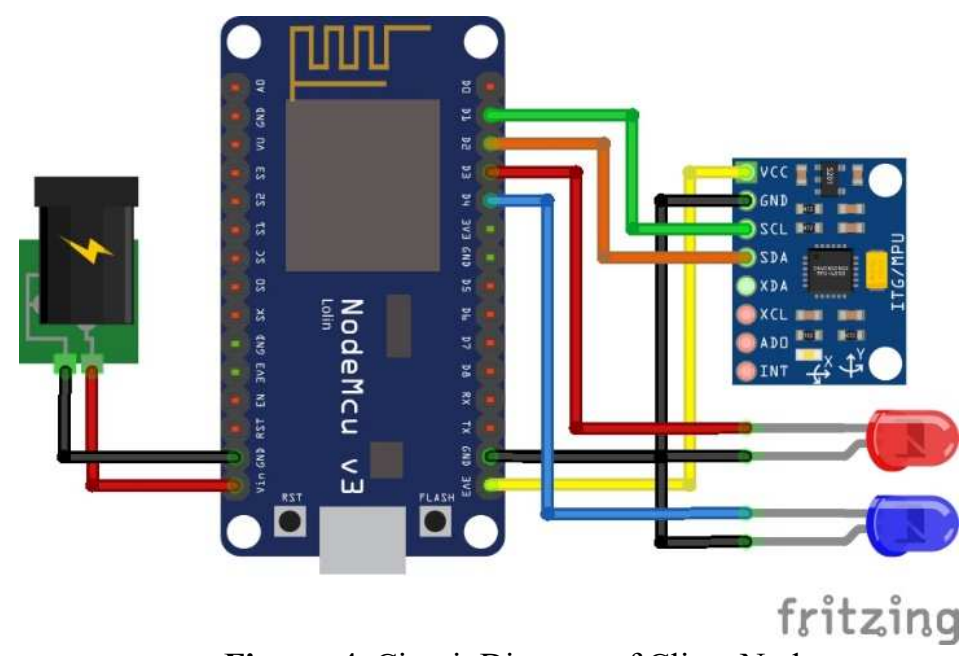

Figure. 4. Circuit Diagram of Client Node

\section{Results and Analysis}

Analysis was carried out on changes in the accelerometer sensor output values, proper acceleration measurements on the accelerometer sensor are recorded when the sensor is moved on axis XYZ which states forward and backward movements for axis $\mathrm{X}$ changes, left and right for $\mathrm{Y}$ axis changes, and up and down for axis $\mathrm{Z}$ changes. This change in the proper acceleration value states whether there is a sponsor or not on the land observed. 


\subsection{Condition of Accelerometer do not move}

Table 1. Accelerometer Sensor Condition do not move

\begin{tabular}{ccccccc}
\hline No & \multicolumn{2}{c}{ Accelerometer Axis } & Sensor Status & The led & Inf. \\
& $\mathrm{Ax}$ & $\mathrm{Ay}$ & $\mathrm{Az}$ & & lights up & \\
\hline $\mathbf{1}$ & 0.07 & 0.08 & 0.85 & Not moving & Blue & Succeeded \\
$\mathbf{2}$ & 0.07 & 0.08 & 0.84 & Not moving & Blue & Succeeded \\
$\mathbf{3}$ & 0.08 & 0.07 & 0.84 & Not moving & Blue & Succeeded \\
$\mathbf{4}$ & 0.08 & 0.07 & 0.84 & Not moving & Blue & Succeeded \\
$\mathbf{5}$ & 0.08 & 0.08 & 0.86 & Not moving & Blue & Succeeded \\
\hline
\end{tabular}

The condition of the accelerometer sensor is not move or ground no movement is a condition where the acceleremeter $\mathrm{X}$ value is more than 0.07 and less than 0.08 , the accelerometer $\mathrm{Y}$ is more than 0.07 and less than 0.08 , and the $\mathrm{Z}$ accelerometer is more than 0.84 and less than 0.86 . This value is the result of testing based on research references, which are listed in Table 1. The data obtained is used as a reference value does not occur ground movement.

\subsection{Condition of Accelerometer Sensor Moves Forward}

The condition of the accelerometer sensor moves forward is a condition where the acceleremeter $\mathrm{X}$ value is less than 0.07 and more than 0.08 based on the research reference accelerometer sensor value conditions, that moving forward produces a negative $X$ accelerometer value, as shown in Table 2. The difference between the axis $\mathrm{X}$ value when the accelerometer sensor is not move and the value of the $\mathrm{X}$ axis when the accelerometer sensor moves forward by amounting to -0.21 becomes the system's reference that the ground moves towards the front of the instrument. This movement can detect landslides with a type of translation landslide movement .

Table 2. Sensor Conditions Moving Forward.

\begin{tabular}{llllll}
\hline No & $\begin{array}{l}\text { The Accelerometer } \\
\text { sensor is idle } \\
\mathrm{Ax}\end{array}$ & $\begin{array}{l}\text { Accelerometer Sensor } \\
\text { Moves forward } \\
\mathrm{Ax}\end{array}$ & Difference & $\begin{array}{l}\text { The led } \\
\text { lights up }\end{array}$ & Inf. \\
\hline $\mathbf{1}$ & 0.07 & -0.27 & & & \\
$\mathbf{2}$ & 0.07 & -0.28 & -0.20 & Red & Moving \\
$\mathbf{3}$ & 0.08 & -0.28 & -0.21 & Red & Moving \\
$\mathbf{4}$ & 0.08 & -0.29 & -0.20 & Red & Moving \\
$\mathbf{5}$ & 0.08 & -0.29 & -0.21 & Red & Moving \\
\hline
\end{tabular}

\subsection{Condition of Accelerometer Sensor moves backwards}

The condition of the accelerometer sensor moves backward is a condition where the acceleremeter $X$ value is less than 0.07 and more than 0.08 based on the research reference accelerometer sensor value condition, that moving backward produces a positive $X$ accelerometer value, as shown in Table 3. The difference between the axis $\mathrm{X}$ value when the 
accelerometer sensor is not move and the value of the $\mathrm{X}$ axis when the accelerometer sensor moves backwards by amounting to 0.31 becomes the system's reference that the ground moves towards the back of the instrument. This movement can detect landslides with a type of translation landslide movement.

Table 3 . Sensor Conditions Moving backwards

\begin{tabular}{cccccc}
\hline No & $\begin{array}{c}\text { The } \\
\text { Accelerometer } \\
\text { sensor is idle } \\
\text { Ax }\end{array}$ & $\begin{array}{c}\text { The Accelerometer } \\
\text { sensor moves } \\
\text { backwards } \\
\text { Ax }\end{array}$ & Difference & $\begin{array}{c}\text { The led } \\
\text { lights up }\end{array}$ & Inf. \\
\hline $\mathbf{1}$ & 0.07 & 0.39 & 0.32 & Red & Moving \\
$\mathbf{2}$ & 0.07 & 0.38 & 0.31 & Red & Moving \\
$\mathbf{3}$ & 0.08 & 0.38 & 0.30 & Red & Moving \\
$\mathbf{4}$ & 0.08 & 0.39 & 0.31 & Red & Moving \\
$\mathbf{5}$ & 0.08 & 0.41 & 0.33 & Red & Moving \\
\hline
\end{tabular}

\subsection{Condition of Accelerometer Sensor moves left}

The accelerometer sensor condition moves to the left side is a condition where the $\mathrm{Y}$ acceleremeter value is less than 0.07 and more than 0.08 based on the research reference accelerometer sensor value conditions, that moving left produces a negative $\mathrm{Y}$ accelerometer value, as shown in Table 4. The difference between the axis $\mathrm{Y}$ value when the accelerometer sensor is not move and the value of the $\mathrm{Y}$ axis when the accelerometer sensor moves left by amounting to -0.36 becomes the system's reference that the ground moves towards the left side of the instrument. This movement can detect landslides with a type of translation landslide movement.

Table 4. Sensor to Left Condition.

\begin{tabular}{cccccc}
\hline No & $\begin{array}{c}\text { The } \\
\text { Accelerometer } \\
\text { sensor is idle } \\
\text { Ay }\end{array}$ & $\begin{array}{c}\text { The } \\
\text { Accelerometer } \\
\text { sensor moves left }\end{array}$ & Difference & $\begin{array}{c}\text { The led } \\
\text { lights up }\end{array}$ & Inf. \\
\hline $\mathbf{1}$ & 0.07 & -0.43 & -0.36 & Red & Moving \\
$\mathbf{2}$ & 0.07 & -0.42 & -0.35 & Red & Moving \\
$\mathbf{3}$ & 0.08 & -0.43 & -0.35 & Red & Moving \\
$\mathbf{4}$ & 0.08 & -0.43 & -0.35 & Red & Moving \\
$\mathbf{5}$ & 0.08 & -0.44 & -0.36 & Red & Moving \\
\hline
\end{tabular}

\subsection{Condition of Accelerometer Sensor moves Right}

The accelerometer sensor condition moves to the right side is a condition where the $\mathrm{Y}$ acceleremeter value is less than 0.07 and more than 0.08 based on the research reference accelerometer sensor value conditions, that moving right produces a positive $\mathrm{Y}$ accelerometer value, as shown in Table 5. The difference between the axis $\mathrm{Y}$ value when the accelerometer sensor is not move and the value of the $\mathrm{Y}$ axis when the accelerometer sensor moves rigrt by amounting to 0.18 becomes the system's reference that the ground moves towards the right side of the instrument. This movement can detect landslides with a type of translation landslide movement. 
Table 5. Sensor to Right Condition.

\begin{tabular}{cccccc}
\hline No & $\begin{array}{c}\text { The Accelerometer } \\
\text { sensor is idle } \\
\text { Ay }\end{array}$ & $\begin{array}{c}\text { The Accelerometer } \\
\text { sensor moves right } \\
\text { Ay }\end{array}$ & Difference & $\begin{array}{c}\text { The led } \\
\text { lights up }\end{array}$ & Inf. \\
\hline $\mathbf{1}$ & 0.07 & 0.24 & 0.17 & Red & Moving \\
$\mathbf{2}$ & 0.07 & 0.25 & 0.18 & Red & Moving \\
$\mathbf{3}$ & 0.08 & 0.24 & 0.16 & Red & Moving \\
$\mathbf{4}$ & 0.08 & 0.24 & 0.16 & Red & Moving \\
$\mathbf{5}$ & 0.08 & 0.26 & 0.18 & Red & Moving \\
\hline
\end{tabular}

\subsection{Condition of Accelerometer Sensor moves Up}

Table 6. Sensor conditions move up.

\begin{tabular}{cccccc}
\hline No & $\begin{array}{c}\text { The Accelerometer } \\
\text { sensor is idle } \\
\mathrm{Az}\end{array}$ & $\begin{array}{c}\text { The Accelerometer } \\
\text { sensor moves up } \\
\mathrm{Az}\end{array}$ & Difference & $\begin{array}{c}\text { The led } \\
\text { lights up }\end{array}$ & Inf. \\
\hline $\mathbf{1}$ & 0.85 & 0.91 & 0.06 & Red & Moving \\
$\mathbf{2}$ & 0.84 & 0.90 & 0.06 & Red & Moving \\
$\mathbf{3}$ & 0.84 & 0.90 & 0.06 & Red & Moving \\
$\mathbf{4}$ & 0.84 & 0.91 & 0.07 & Red & Moving \\
$\mathbf{5}$ & 0.86 & 0.91 & 0.05 & Red & Moving \\
\hline
\end{tabular}

The condition of the accelerometer sensor moves upward is a condition where the acceleremeter $Z$ value is less than 0.84 and more than 0.86 based on the research reference accelerometer sensor value condition, that moving up produces a positive accelerometer $Z$ value, as shown in Table 6 . The difference between the axis $Z$ value when the accelerometer sensor is not move and the value of the $Z$ axis when the accelerometer sensor moves up by amounting to 0.07 becomes the system's reference that the ground moves towards the upward of the instrument. This movement can detect landslides with a type of rotasy avalanches landslide movement.

\subsection{Condition of Accelerometer Sensor moves Down}

The condition of the accelerometer sensor moves downward is a condition where the acceleremeter $Z$ value is less than 0.84 and more than 0.86 based on the research reference accelerometer sensor value condition, that moving down produces a negative $Z$ accelerometer value, as shown in Table 7 . The difference between the axis $Z$ value when the accelerometer sensor is not move and the value of the $Z$ axis when the accelerometer sensor moves down by amounting to -0.77 becomes the system's reference that the ground moves towards the downward of the instrument. This movement can detect landslides with a type of rotasy avalanches landslide movement. 
Table 7. Sensor condition moves down

\begin{tabular}{|c|c|c|c|c|c|}
\hline \multirow[t]{2}{*}{ No } & $\begin{array}{c}\text { The Accelerometer } \\
\text { sensor is idle }\end{array}$ & $\begin{array}{l}\text { The Accelerometer } \\
\text { sensor moves down }\end{array}$ & \multirow[t]{2}{*}{ Difference } & \multirow[t]{2}{*}{$\begin{array}{l}\text { The led } \\
\text { lights up }\end{array}$} & \multirow[t]{2}{*}{ Ket. } \\
\hline & $\mathrm{Az}$ & $\mathrm{Az}$ & & & \\
\hline 1 & 0.85 & -0.08 & -0.77 & Red & Moving \\
\hline 2 & 0.84 & -0.09 & -0.75 & Red & Moving \\
\hline 3 & 0.84 & -0.09 & -0.75 & Red & Moving \\
\hline 4 & 0.84 & -0.09 & -0.75 & Red & Moving \\
\hline 5 & 0.86 & -0.10 & -0.76 & Red & Moving \\
\hline
\end{tabular}

\section{Conclusion}

The accelerometer sensor can be used as a landslide detection tool by recording the proper acceleration value on the $\mathrm{X} \mathrm{Y} \mathrm{Z}$ axis in the sensor. The accelerometer sensor can detect landslides with a type of translation landslide movement by looking at changes in the values of $\mathrm{X}$ and $\mathrm{Y}$ axis and rotasy avalanches by looking at changes in axis $\mathrm{Z}$ values. This system detects landslides after a few moments when ground movements occur. To detect the possibility of a landslide, a system for detecting soil conditions and weather conditions which are common causes of landslides are needed

Acknowledgments. Thank you for Faculty of Engineering at Siliwangi University as a source of funding; Muhamad T Hidayat as research members who have completed this study.

\section{References}

[1] F. Achmad, "Tinjauan Longsoran pada Ruas Jalan Akses - Pelabuhan Gorontalo," in Prosiding Simposium Nasional XIII FSTPT, Universitas Katolik Soegijapranata, 2010, pp. 1-10.

[2] M. V Ramesh, S. Kumar, and P. V. Rangan, "Wireless Sensor Network for Landslide Detection," in Proceedings of The Third International Conference on Sensor Technologies and Applications, SENSORCOMM 2010, IEEE, Greece, 2010, no. 003914.

[3] BNPB, Data Bencana Indonesia 2017. Pusat Data, Informasi dan Humas Badan Nasional Penanggulangan Bencana, 2017.

[4] E. Ata, "Signal Multipath in High Precision Gps Surveys," Tech. Gaz. 21, vol. 4, pp. 707-713, 2014.

[5] Y. Bai et al., "Research and development of electrostatic accelerometers for space science missions at HUST," Sensors (Switzerland), vol. 17, no. 9, pp. 1-18, 2017.

[6] M. V Ramesh, "Real-time Wireless Sensor Network for Landslide Detection," in Third International Conference on Sensor Technologies and Applications, 2009, vol. 09, pp. 405-409.

[7] A. T. Kunnath and M. V Ramesh, "Wireless Geophone Network for Remote Monitoring and Detection of Landslides," vol. 11, pp. 122-125, 2009.

[8] A. Musaev, S. Member, D. Wang, and S. Member, "LITMUS : a Multi-Service Composition System for Landslide Detection,” IEEE Trans. Serv. Comput., vol. 1374, no. c, pp. 1-12, 2014.

[9] P. Lu, A. Stumpf, N. Kerle, and N. Casagli, "Object-Oriented Change Detection for Landslide Rapid Mapping,” IEEE Geosci. Remote Sens. Lett., vol. 8, no. 4, pp. 701-705, 2011.

[10] M. Liao, L. Zhang, and T. Balz, "Post-earthquake landslide detection and early detection of landslide prone areas using SAR,” Urban Remote Sens. Jt. Event, pp. 1-5, 2009. 
[11] S. Aggarwal, P. K. Mishra, K. V. S. Sumakar, and P. Chaturvedi, "Landslide Monitoring System Implementing IOT Using Video Camera,” 2018 3rd Int. Conf. Converg. Technol., pp. 1-4, 2018.

[12] S. L. Shi He, Hong Tang, Jing Li, Zhipeng Tang, "Landslide Detection with Two Satellite Images of Different Spatial Resolutions in a Probabilistic Topic Model," IGARSS, vol. 15, no. 1, pp. 409-412, 2015.

[13] S. Karthik, "Smart Autonomous Self Powered Wireless Sensor Networks based Low-cost Landslide Detection System,” Int. Conf. Circuit, Power Comput. Technol. [ICCPCT] Smart, vol. 15, 2015.

[14] F. M. S. Nursuwars, N. ika Kurniati, and M. T. Hidayat, "Accelerometer sebagai Pendeteksi Dini Pergerakan Tanah,” J. Ilm. Setrum, vol. 8, no. 1, pp. 9-17, 2019.

[15] F. M. S. Nursuwars, "API (Aplication Programing Interface) Mikrotik untuk Otentifikasi Sistem Akademik Universitas Siliwangi,” J. Siliwangi Seri Sains dan Teknol., vol. 4, no. 2, 2018.

[16] A. Rahmatulloh and F. M. S. Nursuwars, "Implementasi Load Balancing, Web Server Menggunakan Haproxy Dan Sinkronisasi File Pada Sistem Informasi Akademik Universitas Siliwangi," J. Teknol. dan Sist. Inf., vol. 3, no. 2, pp. 241-248, 2017.

[17] F. M. S. Nursuwars and A. Rahmatulloh, "RFID for nurse activity monitoring in the hospital's nurse call system with Internet of Thing (IoT) concept," IOP Conf. Ser. Mater. Sci. Eng., vol. 550, p. 012025, 2019. 